Document downloaded from:

http://hdl.handle.net/10251/79896

This paper must be cited as:

Martín Gorriz, B.; Torregrosa, A.; García Brunton, J. (2012). Post-bloom mechanical thinning for can peaches using a hand-held electrical device. Scientia Horticulturae. 144:179-186. doi:10.101016/j.scienta.2012.07.003.

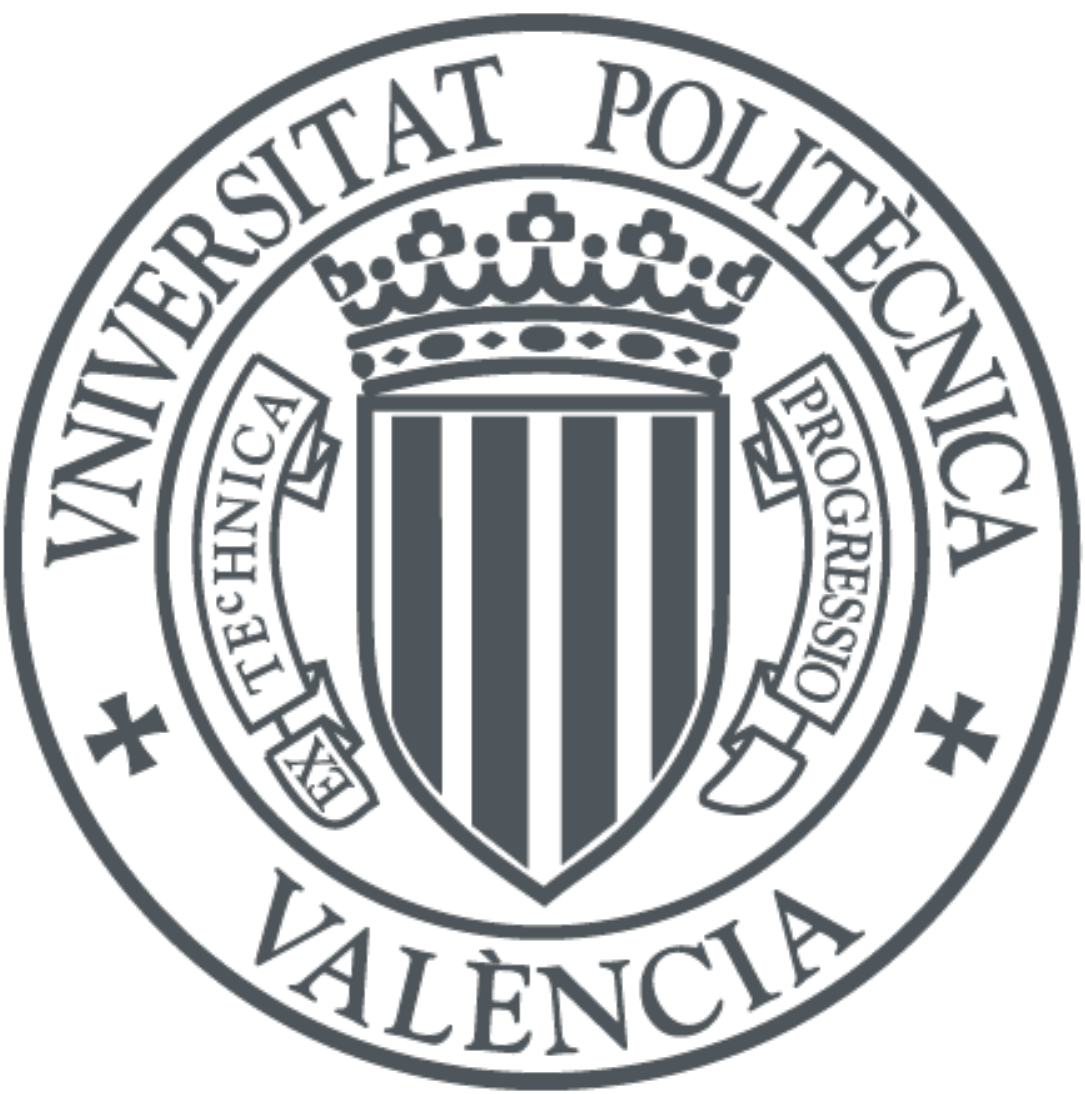

The final publication is available at

http://doi.org/10.1016/j.scienta.2012.07.003

Copyright Elsevier

Additional Information 


\section{Post-bloom mechanical thinning for can peaches using a hand-held electrical}

2 device

3 B. Martin-Gorriz ${ }^{1}$, A. Torregrosa ${ }^{2}$, J. García Brunton $^{3}$

$4{ }^{1}$ Universidad Politecnica de Cartagena. Dpto Ingenieria Alimentos y Equipamiento

5 Agrícola. Paseo Alfonso XIII, no 48. 30203 Cartagena (Spain). E-Mail:

6 b.martin@upct.es

$7 \quad{ }^{2}$ Universitat Politècnica de València. Dpto Ingeniería Rural y Agroalimentaria. Valencia 8 (Spain).

$9 \quad{ }^{3}$ Instituto Murciano de Investigación y Desarrollo Agrario y Alimentario. Murcia 10 (Spain).

12 Abstract:

13 Hand thinning is a necessary but costly practice in peach (Prunus persica L. Batsch)

14 production. A hand-held mechanical device has been tested to thin peach trees, trained 15 in "free Italian vase", 50 to 62 days after full bloom. Hand thinning (HT); mechanical 16 thinning (MT); mechanical and hand thinning (MHT); and un-thinned (UT) were tested 17 from 2008 to 2011 in Murcia, south-eastern Spain. After thinning, the distance between 18 the remaining fruits was measured: the shortest distance was $5.2 \mathrm{~cm}$ for MT, with no 19 significant differences between MHT and HT at 8.6 and $8.8 \mathrm{~cm}$, respectively. The 20 differences in distances did not affect the yield and size of the fruit at harvesting in any 21 of the cases. There were no significant differences between HT, MT and MHT 22 treatments in fruit per tree, mean fruit weight and yield efficiency in the four years the 23 test lasted. Farmers considered the hand-held mechanical device positively because it 24 increased field efficiency. Moreover, with HT the work rate was 2 trees $^{-1}$, with MHT 25 it was 8 trees $\mathrm{h}^{-1}$ and with MT, 23 trees $\mathrm{h}^{-1}$. The most expensive system was HT (4.07€ 
tree $\left.^{-1}\right)$ as opposed to $1.37 €$ tree $^{-1}$ for MHT. The lowest cost was for MT with $0.49 €$ tree ${ }^{-1}$. Moreover, with HT the operating time was $324 \mathrm{~h} \mathrm{ha}^{-1}$, with MHT it was $90 \mathrm{~h} \mathrm{ha}^{-1}$ and with MT, $30 \mathrm{~h} \mathrm{ha}^{-1}$. The most expensive system was HT $\left(2713 € \mathrm{ha}^{-1}\right)$ as opposed to $915 € \mathrm{ha}^{-1}$ for MHT. The lowest cost was for MT with $328 € \mathrm{ha}^{-1}$. The net value of fruit

$30\left(€\right.$ tree $\left.^{-1}\right)$ showed no significant differences between HT, MT, and MHT. Based on our 31 study, MT appears to be a promising technique for thinning peach trees for the canning industry, because although the reduction of production costs is not high in comparison with the total cost of the crop, the increase in work speed is of great interest to thin the trees on the most appropriate dates.

Keywords: Mechanical thinning; Peach; Fruit; Harvest; Prunus Persica; Hand-held thinners.

\section{Introduction}

40 Fruit thinning is one of the most expensive cultural practices in peach production.

41 Removing excess fruit between full bloom to 50 days after bloom is a standard commercial practice to produce large fruit for market. Hand thinning is costly and spend much time, depending on tree size, shape, flower production, thinning intensity and season; in Spain it takes between 25-30 min at flower stage (Martin et al., 2010), in Virginia (USA) 15 min by tree at post-bloom are reported (Marini, 2002) and in

46 California (USA) 60 minutes are used to full bloom thinning (Berlage and Langmo, 1982).

49 Chemical thinning as an option for stone fruit is both limited and unpredictable (Stover and Greene, 2005). It is difficult to find a winning strategy for chemical thinning in 
51 peach because the chemical compounds are strongly limited by environmental

52 conditions (Costa and Vizzotto, 2000). Furthermore, nowadays there is increasing

53 pressure from consumers for the use of less, or ideally no, agrochemicals in fruit

54 production (Webster and Spencer, 2000).

55

56 Attempts to thin peaches by physical or chemical methods have resulted in the

57 unsatisfactory uneven distribution of fruit along shoots or preferential removal of larger

58 fruit (Southwick et al., 1995). However, several authors have demonstrated that it is

59 possible to obtain peaches of marketable sizes without a uniform separation between

60 fruits. Corelli-Grappadelli and Coston (1991) have reported that the effect of fruit

61 position is greater than that of distance between the fruits. Marini and Sowers (1994)

62 have shown that if peaches are thinned non-uniformly throughout the canopy, the lack

63 of thinning individual shoots will be partially compensated by the adequate thinning of

64 most of the tree. Miranda and Royo (2002) have evaluated the effect of the intensity of

65 hand thinning and fruit distribution along the shoot and the yield of different peach

66 cultivars and have concluded that fruit distribution on the shoot had little or no

67 influence over final diameter or yield.

68

69 Existing commercial mechanical tractor-driven thinning equipment requires hedge-

70 trained trees (Baugher et al., 2010; Schupp et al., 2011; Miller et al., 2011; Hehnen et

71 al., 2012), but in south-eastern Spain, the most common training system is the "free

72 Italian vase", where that equipment cannot operate appropriately. Thus, hand-held

73 devices were employed because they can be used in any training system (Martin et al.,

74 2008). 
76 The objective of this study was to evaluate a hand-held mechanical thinning device as

77 an alternative to hand thinning in "free Italian vase" peach trees. Hand thinning, mechanical thinning, mechanical follow-up hand thinning, and no-thinning (control) were compared from 2008 to 2011 in Murcia, south-eastern Spain. The parameters for analysis were thinning time; crop load; fruit size; and economic value of marketable

81 fruit for the canning industry.

82

\section{Materials and Methods}

\subsection{Treatments}

The experiment was conducted between 2008 and 2011 in a peach (Prunus persica L.

Batsch, cv Carson) orchard located in Caravaca (Murcia, Spain). Carson is a mid-season clingstone cultivar grown in Spain for the canning industry. The trees were nine years old at the beginning of the trials and planted in a frame of $5 \mathrm{~m}$ between rows and $3 \mathrm{~m}$ in the row. The trees measured $3 \mathrm{~m}$ in diameter and were $3.5 \mathrm{~m}$ tall. The average trunk height was $0.60 \mathrm{~m}$, and the average trunk diameter was $0.14 \mathrm{~m}$. The main branches were 1.7-2.1 $\mathrm{m}$ long and formed $140-160^{\circ}$ angles with the trunk. The secondary branches were $0.8-1.3 \mathrm{~m}$ long and formed $80-120^{\circ}$ angles with the trunk. The trees were trained to a "free Italian vase" shape and were hand-pruned.

Four treatments were used: determine the number and size of fruits produced by un-thinned trees and also to measure the thinning intensity; but this treatment has no commercial interest since peach trees are always thinned. 
2. Hand thinning (HT): The thinning was done by workers who eliminated green fruits from all the branches on the tree (with or without ladders), leaving one fruit approximately every $10 \mathrm{~cm}$, which is adequate for the canning industry and the fresh market.

3. Mechanical thinning (MT): an electric hand-held fruit remover was used (Volpi, Davide e Luigi Volpi S.p.A. Casalromano, Italy). This device was $2.5 \mathrm{~m}$ long and weighed $2 \mathrm{~kg}$. It had a head with six rotating fingers and was powered by a $12 \mathrm{~V}$ electric motor that operated at two fixed speeds, 714 and $833 \mathrm{rev}$ $\min ^{1}$. After preliminary tests, $714 \mathrm{rev} \min ^{-1}$ was determined to be the most suitable speed for thinning. Electricity was supplied by a 12 V, 75 Ah car battery, which remained on the ground, and a 15-m long electric extension cord. This equipment was chosen because it gave the best results in the preliminary tests of six electrical devices (Martin et al., 2008).

120

121 The experiment was designed as a randomised block, divided into plots; each plot had six trees (replicates). 
125 Thinning dates were April $17^{\text {th }}, 2008$ (50 DAFB); May $7^{\text {th }}, 2009$ (62 DAFB); May $11^{\text {th, }}$

1262010 (53 DAFB); April 28 $8^{\text {th }}, 2011$ (50 DAFB). Harvesting was done when the fruit was

127 visually mature. In 2008 it was done in two passes (130 and 138 DAFB) and in 2009-

1282011 it was done in three passes (in 2009: 130, 136 and 140 DAFB; in 2010: 125, 130

129 and 134 DAFB; in 2011: 133, 138 and 142 DAFB).

130

131 On the first thinning day of 2008-2011, the trunk diameter of each tree was measured at

$13230 \mathrm{~cm}$ above the ground to calculate the trunk cross-sectional area (TCSA). Time

133 consumed for thinning was measured tree by tree.

134

135 Thinning intensity was evaluated in 2008 following the methodology proposed by

136 Berlage and Langmo (1982). A complete sample of green fruit removed at thinning was

137 kept for each tree. This methodology allows to evaluate the thinning intensity, but not

138 the uniformity of fruit distribution on the branches.

139

140 Baugher et al. (1991) measured the fruit density on terminal, middle, and basal fruiting

141 shoot positions before and after trees were thinned. In order to measure fruit spatial

142 distribution, in 2010 and 2011 the thinning intensity was determined by measuring the

143 length of four stems and the distance between green fruits before and after each thinning

144 treatment on each tree. Two short shoots (less than $50 \mathrm{~cm}$ in length) and two long shoots

145 (longer than $50 \mathrm{~cm}$ ) were measured per tree. The distinction between short and long

146 shoots was made because it was noticed that long shoots were easy to thin with the

147 device ; moreover, short shoots were in the inner part of the tree were the device access

148 was more difficult. In 2010, thinning intensity was measured the same day that the trees

149 were thinned (May 11th, 2010; 53 days after full bloom: DAFB). In 2011, thinning 
150 intensity was measured twice on the same shoots: the first time on the thinning day

151 (April 28th, 2011; 50 DAFB) and the second, one month after thinning (80 DAFB).

153 On each harvest date, several parameters were analysed: (i) the fruit harvested from

154 each tree was weighed using an electronic balance with a resolution of $50 \mathrm{~g}$ to

155 determine the yield $\left(\mathrm{kg} \mathrm{tree}^{-1}\right)$ and yield efficiency $\left(\mathrm{g} \mathrm{cm}^{-2} \mathrm{TCSA}\right)$; (ii) the number of

156 fruits per tree (no. fruit tree ${ }^{-1}$ ) was counted, and the crop density (no. fruit $\mathrm{cm}^{-2}$ TCSA)

157 was calculated; (iii) the fruit weight $\left(\mathrm{g}_{\text {fruit }}{ }^{-1}\right.$ ) was obtained indirectly by dividing the

158 yield per tree by the number of fruits; and (iv) the fruit size category (\% no. fruit tree ${ }^{-1}$

159 and $\mathrm{kg}$ tree ${ }^{-1}$ ) was obtained from a sample of 150 fruits per tree. This was measured

160 using an electronic calliper with $0.1 \mathrm{~mm}$ resolution. The fruits collected were divided

161 into two categories based on their calibre: fruits over $55 \mathrm{~mm}$, which is the minimum

162 size accepted by the canning industry, and fruits under $55 \mathrm{~mm}$. Thinning operations

163 were recorded with a camcorder, and the time required to thin each tree was measured

164 to calculate the thinning costs.

165

166 To evaluate quality parameters, on each harvest date, a sample of 100 fruits was taken.

167 Several parameters were analysed: (i) the flesh firmness was measured by means of a

168 Magness-Taylor style penetrometer probe (Fruit Pressure Tester, FT-327, Facchini

169 SRL, Alfonsine, Italy) equipped with an $8 \mathrm{~mm}$ diameter probe (section $50 \mathrm{~mm}^{2}$ ); (ii) the

170 soluble solids concentration in the fruits was determined from juice samples using a

171 hand refractometer (Atago Pocket Pal-1, Atago Co. Ltd., Tokyo, Japan); and (iii) the

172 level of acidity was obtained by neutralising $1.5 \mathrm{~mL}$ of the squeezed, spin-dried and

173 filtered juice with $0.1 \mathrm{~N} \mathrm{NaOH}$, using a digital $\mathrm{pH}$ meter (Crison $\mathrm{pH}$ Burette 24, Crison 
174 Instruments S.A., Barcelona, Spain). The results were expressed in terms of the

175 dominant acid as grams of malic acid per litre ( $\mathrm{g}$ malic acid $\left.\mathrm{L}^{-1}\right)$.

176

177 Statistical analyses were performed using a commercially-available statistics package

178 (Statgraphics Plus, version 5.1., STSC Inc., Rockville, MD, USA).

179

180 The cost of thinning by treatment was calculated as follows:

181

182

183

184

185

186

187

188

190

191

192

193

194 The economic profit of the thinning treatments was calculated considering the yield (kg

196

197

- Hand thinning costs were based on a labour rate of $8.30 € \mathrm{~h}^{-1}$, including taxes.

- Mechanical thinning costs were calculated following ASAE D497.7 (2011) and ASAE EP496.3 (2011). The economic costs for the mechanical device were based on a machine life of five years or $1200 \mathrm{~h}$ of use (commercially available price of $€ 1530$ ), an annual usage of $240 \mathrm{~h}$, an interest rate of $7 \%$, a salvage value of $12 \%$ of the purchase price, storage at $0.75 \%$ of the purchase price and cumulative repair and maintenance costs at $82 \%$ of the purchase price. The cost of the mechanical device was $2.44 € \mathrm{~h}^{-1}$ and the cost of hand-labour was $8.30 €$ $\mathrm{h}^{-1}$. The total cost of the mechanical thinning treatment was $10.74 € \mathrm{~h}^{-1}$.

- Mechanical and hand thinning treatment was carried out by a team of three workers; one removed the fruits with mechanical device $\left(10.74 € \mathrm{~h}^{-1}\right)$ and the other two thinned by hand after mechanical thinning $\left(8.30 € \mathrm{~h}^{-1}\right)$.

tree $^{-1}$ ) of fruits with a size over $55 \mathrm{~mm}$. The price for canning peaches was $0.44 € \mathrm{~kg}^{-1}$ in 2008; $0.33 € \mathrm{~kg}^{-1}$ in $2009 ; 0.43 € \mathrm{~kg}^{-1}$ in 2010 ; and $0.22 € \mathrm{~kg}^{-1}$ in 2011 . These peach prices were obtained from the wholesale weekly prices received by producers in the 
198 field (CARM, 2011). The thinning cost $\left(€\right.$ tree $\left.^{-1}\right)$ was subtracted from the production

199 value $\left(€\right.$ tree $\left.^{-1}\right)$ to obtain the net margin.

200

\section{3. Results}

\section{3.1. Effect of thinning on distance between green fruits}

203 Although the objective for the three treatments was for the same number of fruits to

204 remain per tree, hand thinning (HT) was the treatment that removed most fruits;

205 mechanical thinning (MT) detached 64\% compared with HT, and mechanical followed

206 by hand thinning (MHT) removed $78 \%$ of HT.

207

208 The effect on the distance between fruits due to the factors: treatment, shoot length, date

209 of measure, distance, and year was analysed with a multi-factorial analysis of variance

210 for the years 2010 and 2011, with the effect of all the factors being significant, with the

211 exception of that of year.

212

213 In the UT trees, the distance between green fruits was $3.6 \mathrm{~cm}$, MT left the green fruits at

214 a significantly greater distance $(5.2 \mathrm{~cm})$ than UT, but at a significantly lower distance

215 than those of MHT and HT, of 8.6 and $8.8 \mathrm{~cm}$, respectively, with no significant

216 differences between the latter two.

217

218 Before thinning, there were no significant differences in the distance between green

219 fruits in short $(3.4 \mathrm{~cm})$ and long $(3.6 \mathrm{~cm})$ shoots. After thinning, there were significant

220 differences in the distance of the green fruits located on short shoots, $4.7 \mathrm{~cm}$, compared

221 with the long shoots, $5.8 \mathrm{~cm}$. This means that the long shoots were thinned more

222 intensively than the short ones. 
224 In 2011 the distance between green fruits was measured on two dates, 50 DAFB, which was the thinning day, and also 80 DAFB (Table 1). In all the treatments the distance increased from the first to the second date, due to the falling of fruits damaged in the thinning operation but not totally removed and due to natural causes. In all the cases in which thinning was carried out, the differences in the distances were low and not significant, but in the case of UT the distance increased significantly, passing from 3.2 to $4.3 \mathrm{~cm}$. This physiological drop has been noticed in some peach varieties when the load is high, due to the competition for nutrients between fruits (Blanco, 1987; Blanco and Socias, 1988; Byers, 1989; Costa et al., 1982; Miranda and Royo, 2002). Thus, to have a precise vision of fruit distance between fruits in thinning treatments, the distance must be measured some days after the operation has been done, in this case roughly one month later.

\subsection{Thinning time and thinning cost}

238 Thinning time was significantly different for HT, MT and MHT treatments in the four

239 years of trials (Table 2). In this experiment, HT was carried out following the farmer's

240 normal practices and took 25-32.7 min tree ${ }^{-1}$ depending on the year, and was therefore

241 the most time-consuming treatment. These results agree with those obtained by Berlage 242 and Langmo (1982); Marini (2002) and Martin et al. (2010).

244 Mechanical thinning required 2-3.3 min tree ${ }^{-1}$ which meant that it was the least time-

245 consuming treatment. It saved $87-93 \%$ of time with respect to HT, which supposes a

246 substantial increase in the work rate, which was 18.9-30.3 trees $\mathrm{h}^{-1}$ versus 1.9-2.4 trees

$247 \mathrm{~h}^{-1}$ for HT. 
249 In 2008, MHT (using ladders to do the follow-up hand thinning) lasted 13.4 min tree $e^{-1}$.

250 In 2009-2011, ladders were not employed and the operators who carried out the follow-

251 up thinning were forced to follow the rhythm of the thinner. This reduced the thinning

252 time to 5.3-10.8 min tree ${ }^{-1}$, allowing a saving time of $67-82 \%$ with respect to HT. In the

253 MHT treatment, the use of ladders in the follow-up thinning did not improve the size of

254 the fruit harvested (Martin et al., 2010).

255

256 Mechanical thinning and MHT reduced thinning time and increased the work rate,

257 which as an average for the four years was 2 trees $\mathrm{h}^{-1}$ for HT, 8 trees $\mathrm{h}^{-1}$ for MHT and

25823 trees $\mathrm{h}^{-1}$ for MT. This increase in the work rate is considered positive by producers

259 because they can work faster, thinning on the best dates and using only well-trained

260 operators.

261

262 Thinning costs were significantly different between HT, MT and MHT treatments.

263 Thinning cost was on average $4.07 €$ tree $^{-1}$ in HT; $1.37 €$ tree $^{-1}$ in MHT and $0.49 €$ tree $^{-1}$

264 in MT. In comparison with HT, MT and MHT produced savings of $88 \%$ and $66 \%$,

265 respectively.

266

267 3.3. Fruit harvested

268 The control treatment (UT) was significantly different from all of the others (HT, MT,

269 and MHT) for the factors: fruit per tree; crop density; mean fruit size; mean fruit

270 weight; yield; and yield efficiency in the four years (Table 3).

271 
272 In the thinning treatments (HT, MT, and MHT) there were no significant differences in

273 number of fruits per tree; crop density (no. $\mathrm{cm}^{-2}$ TCSA); and yield efficiency $\left(\mathrm{g} \mathrm{cm}^{-2}\right.$

274 TCSA).

275

276 Thinning treatments reduced, on average for the four years, the number of fruits per tree

277 by between $50-60 \%$ as compared to UT. Similar values are reported by other

278 researchers such as Schupp et al. (2008) who reduced crop load by an average of 58\%

279 using drum shaker devices, and Myers et al. (2002) consider that 50\% is a standard

280 degree of thinning in peaches. However, a major difficulty of thinning is to find the

281 optimal thinning intensity. This is so because the optimum thinning level to maximise

282 grower profit will depend on many factors, including yield; fruit size; fruit size

283 distribution; minimum size standards; etc.

There were also significant differences in fruit size and fruit weight (Table 3) of UT in comparison with the three thinning treatments (HT, MT, and MHT). Peach fruit size is negatively related to the number of fruit per tree (Johnson and Handley, 1989). Hand thinning, MT and MHT treatments increased fruit size $(\mathrm{mm})$ by $10 \%$, and fruit weight $\left(\mathrm{g}\right.$ fruit $^{-1}$ ) by $47 \%$ on average for the four years as compared to UT. On the other hand, yield $\left(\mathrm{kg} \mathrm{tree}^{-1}\right)$ was reduced by $31 \%$ in HT, MT and MHT with respect to UT.

292 Figure 1 shows the distribution (\%) of fruit diameters for all the treatments. In UT, 18\% 293 of fruit had a calibre of less than $55 \mathrm{~mm}$, which is the minimum calibre accepted by the 294 industry. This percentage was considerably lower in the thinning treatments: $8 \%$ in MT, $4 \%$ in MHT, and 3\% in HT. 
297 The average fruit weight was linearly correlated with the fruit number per tree. Johnson

298 and Handley (1989) and Marini and Sowers (1994) have proposed a relationship

299 between average fruit weight and fruit number as a linear equation $\mathrm{y}=\mathrm{mx}+\mathrm{b}$. Using

300 our data, a mathematical relationship was established between average fruit weight ( $\mathrm{y}, \mathrm{g}$

301 fruit $^{-1}$ ) and crop density (x, number fruit $\mathrm{cm}^{-2}$ TCSA). The following formula was

302 obtained: $\mathrm{y}=200.3-13.7 \mathrm{x}\left(\mathrm{R}^{2}=69 \%\right.$; P<0.05) (Fig. 2). Johnson and Handley (1989)

303 obtained a $\mathrm{R}^{2}$ value between $67 \%$ and $92 \%$ comparing peach cultivars in early, mid- and

304 late-season. The linear relationship was significant but the slope depended on the

305 cultivar. "Carson" is a mid-season ripening cultivar. With our data, crop density

306 explained $69 \%$ of the variability in fruit weight, and thus other factors must also

307 influence fruit weight. Miranda and Royo (2002) established a mathematical

308 relationship between fruit diameter and precocity, pruning load, and crop density which

309 explained $55 \%$ of the variability in fruit diameter.

310

311 Since yield efficiency is a product of fruit weight and crop density, Johnson and

312 Handley (1989) proposed a relationship between average fruit weight and crop density

313 using a curvilinear equation of the form $\mathrm{y}=\mathrm{mx}^{2}+\mathrm{bx}$. Using our data, a mathematical

314 relationship was established between average yield efficiency ( $\mathrm{y}, \mathrm{g} \mathrm{cm}^{-2}$ TSCA) and

315 crop density (x, number fruit $\mathrm{cm}^{-2}$ TCSA). The following formula was obtained: $\mathrm{y}=-$

$3160.0127 \mathrm{x}^{2}+0.195 \mathrm{x}\left(\mathrm{R}^{2}=82 \% ; \mathrm{P}<0.05\right)($ Fig. 2$)$.

317

318 These two relationships obtained for "Carson" cultivar (Fig. 2) may be a useful tool to

319 determine firstly, the thinning intensity needed to obtain the desired fruit weight; and

320 secondly, to estimate yield efficiency for the thinning intensity selected. 


\subsection{Physical-chemical properties of fruits}

323 Flesh firmness decreases with maturation and ripeness of stone fruits. Typical firmness

324 levels at normal commercial maturity of mid-season peaches are 45-55 N (Kader and

325 Mitchell, 1989). As shown in Table 4, average flesh firmness decreased from the first to

326 the last harvest date; although in 2010 and 2011 the flesh firmness values obtained on

327 the first day of harvest were lower than those in 2008 and 2009.

328

329 Soluble solids concentration was always greater on the first picking date, due to the

330 selective manual harvesting (Table 4). On the first dates, workers take only the biggest

331 and most coloured fruits, meanwhile on the last, they take all the remaining fruits of the

332 tree, whatever their state of maturity.

333

334 Acidity increased with the time, which can be explained by the fact that the last fruits

335 were immature.

336

337 3.5. Economical aspects

338 The highest total yield was obtained with UT (100 kg tree ${ }^{-1}$ on average for four years).

339 Despite 10\% not having reached the commercial minimum size of $55 \mathrm{~mm}$ (Table 5) yet,

340 a higher yield was observed in this treatment than in the others. In all the years, UT fruit

341 had a higher gross value and net value than those of all thinning treatments.

343 There were no significant differences in total yield between HT, MT and MHT during

344 the four years. Hand thinning was the treatment that produced the least non-commercial

345 peaches (1\%), versus 5\% in MT and 2\% in MHT, although these differences were not 
346 significant. Despite that, there were no significant differences in yield of commercial

347 sizes, gross and net value of fruit among HT, MT and MHT.

349 The treatment with higher net value was UT with $32 €$ tree $^{-1}$, meanwhile HT, MT and 350 MHT reached $20 €$ tree $^{-1}, 22 €$ tree $^{-1}$ and $23 €$ tree $^{-1}$, respectively.

\section{Discussion}

By definition, successful thinning results in a reduction in crop load and in an increase of the fruit size. Unfortunately, reducing crop load is also likely to reduce yield. Historically, it has been assumed or implied that a significant increase in fruit size will compensate for the loss of yield that typically results from thinning. For example, in 1903 Walker urged peach growers in Arkansas to remove $1 / 2$ to $3 / 4$ of the small fruit, promising that the value of the fruit would be increased sufficiently to pay $1000 \%$ of the cost of thinning, with no reference to the value of the lost fruit. However, it is clear that a reduction in total yield is only beneficial if sufficiently more fruit can be marketed or marketed at a higher price. Silsby et al. (1991) report that it is possible that improvement in fruit size and quality did not compensate for loss of yield.

364 In this test, thinning treatments (HT, MT and HMT) reduced the number of fruits per tree with respect to UT by an average of $45 \%$, being the average yield of UT trees 100

$366 \mathrm{~kg}$ tree $^{-1}$ versus $69 \mathrm{~kg}$ tree $^{-1}$ of HT, MH, and MHT (Table 3). Obviously, the size in

367 these last treatments was higher, $66 \mathrm{~mm}$ versus $60 \mathrm{~mm}$ in UT. Generally when the fruit 368 is for the fresh market, the increase in size can compensate the yield losses due to the 369 strong differences in prices by calibre, but for processing peaches, fruit size is not the 370 most important determinant of price, because all fruit greater than $55 \mathrm{~mm}$ in diameter 
receive the same price. Thus, in our trials, UT reached an average net value of $31.92 €$

372 tree $^{-1}$, meanwhile HT, MT, and MHT obtained 20.09, 21.97, 22.92 $€$ tree $^{-1}$ respectively

373 (Table 5).

374

375 The practice of fruit thinning has been used for hundreds, perhaps thousands, of years to 376 manipulate cropping and blooming in peach (Dennis, 2000). Although in this test UT

377 was the best economical solution, farmers will never leave the trees un-thinned because

378 the non-commercial fraction (10\% in this case) also supposes costs in harvesting and managing fruit. Moreover, thinning can influence fruit quality parameters. Link (2000)

380 showed that thinning improves fruit size, colour and is accompanied by higher contents

381 of soluble solids. Thinning therefore improves the taste and also the appearance of the

382 fruit. Unfortunately, in our test the quality of the fruit was not analysed for the different 383 treatments.

There were no significant differences between HT, MT, and MHT treatments in fruit per tree, mean fruit weight, and yield efficiency (Table 3). Consequently, for this

387 cultivar, independently of the thinning method used, the size and yield of fruit can be estimated depending on crop density (Fig. 2) and assuming a spectrum of probable prices for the fruit size, to estimate the yield net value. Scott and Rasmussem (1990) developed a mathematical model to optimise the thinning intensity in peaches using easily measurable parameters. Mathematical models are useful tools for optimising thinning, but the parameters must be obtained for any particular agricultural situation.

394 Some cultivars of stone fruits tend to develop a pattern of biennial bearing that may vary greatly in intensity (Seehuber et al., 2011). Thinning reduced the fluctuation in 
396 yield, but the fruit size result in a single year is not representative. Mechanical thinning

397 is the most "environmentally friendly" and cheaper system to thin peaches.

398

399 5. Conclusions

400 Both treatments which employ a hand-held mechanical device (MT and MHT) have

401 allowed a considerable reduction in the thinning time, $90 \%$ with MT and $75 \%$ with

402 MHT, with respect to hand-thinning (HT). The operating time with HT was $324 \mathrm{~h} \mathrm{ha}^{-1}$,

403 with MHT it was $90 \mathrm{~h} \mathrm{ha}^{-1}$ and with MT, $30 \mathrm{~h} \mathrm{ha}^{-1}$.

404

405 The highest thinning cost was for HT with $2713 € \mathrm{ha}^{-1}$. Due to the reduced value of the

406 thinning in comparison with the increase in the work rate, mechanical thinning

407 treatments supposed a considerable saving in thinning costs, $88 \%$ and $66 \%$ savings for

408 MT and MHT respectively, with respect to HT.

409

410 There were no significant differences between HT, MT, and MHT treatments in fruit

411 per tree, mean fruit weight, yield efficiency and net value of fruit in any of the four

412 years of the test. Thus, MT is the best option, because it was the least expensive and the

413 yield and fruit size obtained were not different from the other thinning treatments.

414

415 The used of hand-held mechanical devices will permit growers to optimise the net

416 return that can be obtained for a specific orchard.

417

418 Acknowledgements 
419 This research was funded by the Consejería de Agricultura de la Región de Murcia,

420 Spain. The authors thank Eng. Regino Aragón (IMIDA) and Marín Giménez Hermanos

421 S.A. (Caravaca, Spain) for their support.

422

\section{References}

424 ASAE D497.7, 2011. Agricultural machinery management data. ASABE Standards, 8 425 pp.

426

427

ASAE EP496.3, 2011. Agricultural machinery management. ASABE Standards, 6 pp.

428

Baugher, T.A., Elliot, K.C., Leach, D.W., Horton, B.D., Miller, S.S., 1991. Improved

430 methods of mechanically thinning peaches at full bloom. J. Am. Soc. Hort. Sci. 116 (5),

431 766-769.

432

433 Baugher, T.A., Ellis, K., Remcheck, J., Lesser, K., Schupp, J., Winzeler, E., Reichard 434 K., 2010. Mechanical string thinner reduces crop load at variable stages of bloom 435 development of peach and nectarine trees. Hortscience 45(9), 1327-1331.

436

437 Berlage, A.G., Langmo, R.D., 1982. Machine vs. hand-thinning of peaches. Trans. of 438 the ASAE $25(3), 538-548$.

439

440 Blanco, A., 1987. Fruit thinning of peaches trees (Prunus persica (L.) Batsch): The 441 effect of paclobutrazol on fruit drop and shoot growth. J. Hort. Sci. 62 (2), 147-155. 442 
443 Blanco, A., Socias, R., 1988. Caída de frutos en el melocotonero de carne amarilla dura

444 'Sudanell-1'. Investigaciones Agraria, Prod. Veg. 3, 45-57.

445

446 Byers, R.E., 1989. Response of peach trees to Bloom thinning. Acta Hortic. 254, 125-

447132.

448

449 CARM, 2011. Estadistica Agraria Regional. Available at: http://www.carm.es/.

$450 \quad$ Accessed 14 October 2011.

451

452 Corelli-Grappadelli, L., Coston, D. C., 1991. Thinning pattern and light environment in 453 peach tree canopies influence fruit quality. Hortscience 26, 1464-1466.

454

455 Costa, G., Grandi, M., Giulivo C., Ramina, A., 1982. Fruit load and tree vigor as related 456 to the natural and CEPA-induced abscission in immature "Andros" cling peaches. Riv.

457 Ortoflorofrutt. It. 66, 297-303.

458

459 Costa, G., Vizzotto, G., 2000. Fruit thinning of peach trees. Plant Growth Regul. 31, $460 \quad 113-119$.

461

462 Dennis, F.G.Jr., 2000. The history of fruit thinning. Plant Growth Regul. 31, 1-16.

463

464 Hehnen, D., Hanrahan, I., Lewis, K., McFerson, J., Blanke, M., 2012. Mechanical

465 flower thinning improves fruit quality of apples and promotes consistent bearing. Sci.

466 Hortic.134, 241-244. DOI: 10.1016/j.scienta.2011.11.011.

467 
Johnson, R.S., Handley, D.F., 1989. Thinning response of early mid and late-season

peaches. J. Amer. Soc. Hort. Sci. 114, 852-855.

470

471 Kader, A.A., Mitchell, F.G., 1989. Maturity and quality. In: La Rue, J.H., Johnson, R.S.,

472 (Eds.). Peaches, plums and nectarines: growing and handling for fresh market.

473 University of California, Publication No. 3331, pp. 191-196.

474

475 Link, H., 2000. Significance of flower and fruit thinning on fruit quality. Plant Growth

476

Regul. 31, 17-26.

477

478 Marini, R.P., 2002. Heading fruiting shoots before bloom is equally effective as

479 blossom removal in peach crop load management. Hortscience 37(4), 642-646.

480

481 Marini, R.P., Sowers, D.L., 1994. Peach fruit weight is influenced by crop density and

482 fruiting shoot length but not position on the shoot. J. Am. Soc. Hortic. Sci. 119 (2),

$483 \quad 180-184$.

484

485 Martin, B., Torregrosa, A., García Brunton, J., Bernad Godina, J.J., Aragón, R., 2008.

486 Preliminary tests of mechanical thinning of peaches for processing industry.

487 International Conference on Agricultural Engineering. AgEng 2008. 23-25 Jun 2008.

488 Hersonissos, Crete - Greece.

489

490 Martin, B., Torregrosa, A., Garcia Brunton, J., 2010. Post-bloom thinning of peaches

491 for canning with hand-held mechanical devices. Sci. Hortic. 125(4), 658-665. DOI:

$492 \quad 10.1016 /$ j.scienta.2010.05.025. 
494 Miller, S., Schupp, J., Baugher, T., Wolford, S., 2011. Performance of mechanical

495 thinners for bloom or green fruit thinning in peaches. Hortscience 46, 43-51.

496

497 Miranda, C., Royo, J.B., 2002. Fruit distribution and early thinning intensity influence

498 fruit quality and productivity of peach and nectarine trees. J. Am. Soc. Hortic. Sci. 127

499 (6), 892-900.

500

501 Miranda, C., Royo, J.B., 2003. A statistical model to estimate potential yields in peach

502 before bloom. J. Am. Soc. Hortic. Sci. 128 (3), 297-301.

503

504 Myers, S.C., Savelle, A.T., Tustin, D.S., Byers, R.E., 2002. Partial flower thinning

505 increases shoot growth, fruit size, and subsequent flower formation of peach.

506 Hortscience 37, 647-650.

507

508 Schupp, J.J., Baugher, T. Auxt, Miller, S.S., Harsh, R.M., Lesser, K.M., 2008.

509 Mechanical thinning of peach and apple trees reduces labor input and increases fruit

510 size. Horttechnolgy 18 (4), 660-670.

511

512 Schupp, J.R., Baugher, T. Auxt., 2011. Peach blossom string thinner performance

513 improved with selective pruning. Hortscience 46(11), 1486-1492.

514

515 Scott, R., Rasmussem, J.M., 1990. Peach thinning optimization model. Acta Hortic.

$516276,247-255$.

517 
518 Seehuber, C., Damerow, L., Blanke, M., 2011. Regulation of source: sink relationship,

519 fruit set, fruit growth and fruit quality in European plum (Prunus domestica L.)-using

520 thinning for crop load management. Plant Growth Regul. 65, 335-341. DOI

$521 \quad 10.1007 / \mathrm{s} 10725-011-9606-\mathrm{x}$.

522

523 Silsby, K.J., Robinson, T., Dellamano, F., 1991. Empire hand thinning study. Proc. New

524 York State Hort. Soc. 136, 175-185.

525

526 Southwick, S.M., Weis, K.G., Yeager, J.T., Zhou, H., 1995. Controlling cropping in

527 'Loadel' cling peach using gibberellin: Effects of flower density, fruit distribution, fruit 528 firmness, fruit thinning, and yield. J. Amer. Soc. Hort. Sci. 120, 1087-1095.

529

530 Stover, E.W., Greene, D.W., 2005. Environmental effects on the performance of foliar 531 applied plant growth regulators. Horttechnology 15, 214-221.

532

533 Walker, E., 1903. Peach growing in Arkansas. Ark. Expt. Sta., Fayetteville, Bul 79, pp $534 \quad 42-68$.

535

536 Webster, A.D., Spencer, J.E., 2000. Fruit thinning plums and apricots. Plant Growth

537 Regul. 31, 101-112. 